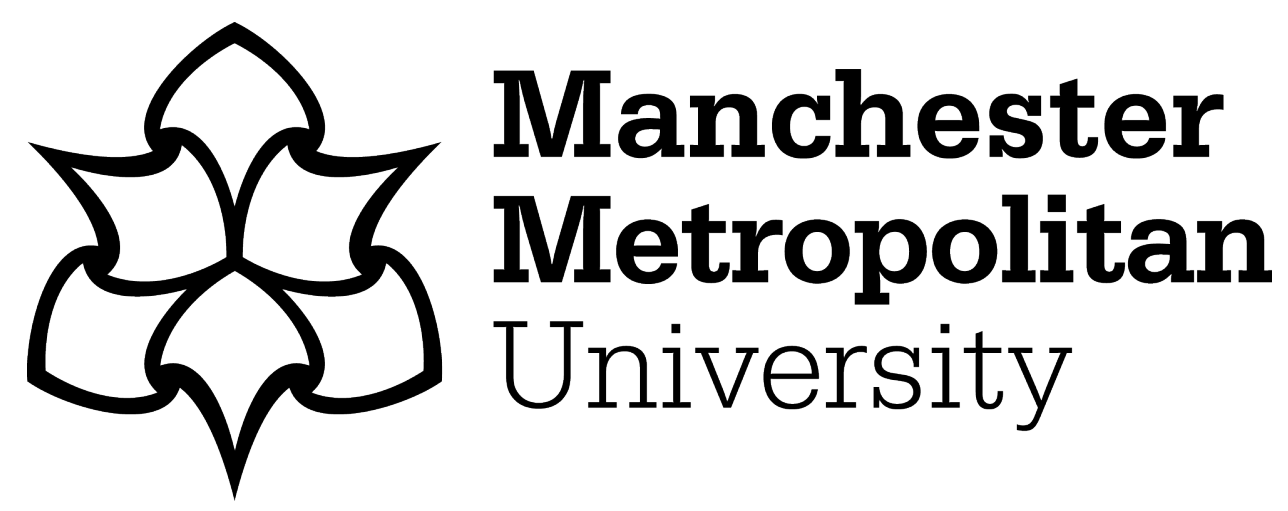

James, Gary and Cooke, Martyn (2017) Myths, truths and pioneers: the early development of association football in The Potteries. Soccer and Society, 19 (1). pp. 5-23. ISSN 1466-0970

Downloaded from: https://e-space.mmu.ac.uk/618862/

Version: Accepted Version

Publisher: Taylor and Francis

DOI: https://doi.org/10.1080/14660970.2016.1276247

Please cite the published version 


\title{
Myths, truths and pioneers: The early development of association football in The Potteries
}

\author{
Martyn Dean Cooke \& Gary James
}

\begin{abstract}
Despite a wealth of academic research focusing on the origins and development of association football in Britain during the nineteenth century, academics have failed to reach a consensus regarding the early history of the game with the emergence of contrasting 'orthodox' and 'revisionist' interpretations. Much of the current research has focused on tackling the subject on a national level and this has resulted in many towns, cities and regions across the country being overlooked when sports historians discuss the origins of modern football. One such region is North Staffordshire, more commonly referred to as The Potteries, which, despite having played a key role in the formation of the Football League, possessing one of the oldest professional football clubs in the country and an early county football association, has never been the subject of an in-depth academic study. Using a range of archival sources this paper provides an overview of the origins and early development of association football across The Potteries from the 1850 to $1870 \mathrm{~s}$, emphasising the influence of Stoke City Football Club and provides a fact based resolution to the debate surrounding the club's origin and formation. The wider development of the game in The Potteries is also explored, tracing the early informal football activities taking place at fairs, fetes and the wakes holidays to the establishment of a football culture in the 1870 s following the formation of organised football clubs and the Staffordshire Football Association. This paper concludes that neither the orthodox nor the revisionist interpretations of the game's origins can fully explain the region's football development and that further research into the region is required to understand the significance of The Potteries in relation to the national picture.
\end{abstract}

Department of Exercise and Sport Science, Manchester Metropolitan University (Cheshire Faculty), Crewe, England.

CONTACT: martyn.cooke@mmu.ac.uk

KEYWORDS: The Potteries, Association Football, Origins, Stoke City, Orthodox, Revisionist

\section{Introduction}

Association football is one of the most prevalent sporting pursuits in the world with professional and amateur teams, clubs, leagues and competitions existing across the globe. The popularity of the modern game was demonstrated during summer 2016, where an estimated two billion viewers tuned in to watch the 2016 European Championships which were hosted in France. ${ }^{1}$ However, despite the widespread interest in the game and increasing participation figures in grassroots football in England, it was not until the publication of Eric Dunning and Kenneth Sheard's Barbarians, Gentleman and Players in 1979 that the origins of the game in Britain were explored rigorously within an in-depth academic study. ${ }^{2}$ Much has been written about the 'birth' and origins of modern association football in the ensuing three decades with an increasing number of academics making significant and progressive contributions to the existing body of literature. However, this research has failed to distinguish a common theme and two competing narratives, described as 'orthodox' and 'revisionist' positions, have emerged with regard to the historiography of nineteenth century 
football. ${ }^{3}$ For a long time, the traditional view promoted by those supporting the orthodox position led by Graham Curry and Eric Dunning, have stressed the importance of public schools and universities in the development of the game, and this was widely accepted by historians and the wider football history community as fact. ${ }^{4}$ More recently, this paradigm has been challenged by academics, notably Adrian Harvey and Peter Swain, who have presented a revised narrative, with studies suggesting that the lower-middle classes were more relevant in the expansion of football and arguing that public schools were not as influential as first thought, while others, such as Gavin Kitching, Tony Collins and Gary James have attempted to seek consensus. ${ }^{5}$ This research has helped to establish association football history as a vibrant and active area of study with the on-going 'origins of football debate' proving particularly vigorous.

Much of the traditional research regarding the 'birth' of modern football has tended to focus on the theme at a broad, national level. However, such countrywide studies cannot fully address the issues surrounding the origins debate because the growth of the game in one specific region or city may not necessarily be representative of other areas and, in recent years, there has been a growth in interest of regional footballing cultures. This has led to a number of studies into the development of football being undertaken with an emphasis on specific conurbations, including Sheffield, Manchester and Liverpool, and regions such as Lancashire. ${ }^{6}$ It is suggested that this type of research will help to build a clearer picture of how the game originated and developed across the country whilst significantly adding to the current debate. Whilst some studies have been conducted with a focus on specific localities, there are areas of the country that remain overlooked in terms of historical research exploring the association football activities and the development of the game occurring on a local level. One such region is 'The Potteries', which comprises six towns, including Stoke-on-Trent, and the neighbouring boroughs. Despite the area being positioned in a centralised location in the Midlands, possessing what is regarded as the second oldest professional football club in the country, Stoke City, and retaining an abundant football culture, the region has never been the focus of an in-depth academic study examining its sporting history. The significance of the region has been referred to by some academics but, whilst Stoke City tend to be the centre of interest due to the club's current standing in the game, the achievements of other individuals and clubs within the region and their influence on the development of football on a national level often go unnoticed. For example, the area has retained two professional football clubs in the region for over a century, a considerable accomplishment for a conurbation of its size, with Port Vale becoming founding members of the Football League Second Division in 1892. ${ }^{7}$ Compared to other cities and regions, it is apparent that a prominent association football culture existed early in the mid-nineteenth century within The Potteries and the establishment of the Staffordshire Football Association in 1877, which was based initially in Stoke, precedes those formed in Lancashire (1878), Nottingham (1882), Manchester (1884) and Liverpool (1892) and positions it as one of the earliest formed county football associations in England.

This paper contributes to the on-going origins of football debate by providing an initial exploration of the origins and development of association football activity in The Potteries during the nineteenth century. In addition to this, the article will resolve the myths and traditional narratives that encompass the early football activity in the region, specifically regarding the introduction of the game to the area and the uncertainty regarding the formation of Stoke City. Finally, suggestions for further research will be made with a view to exploring the significance of the region and demonstrating its national influence.

\section{The Potteries}


The city of Stoke-on-Trent is located in North Staffordshire, England, and is situated midway between the sprawling industrial landscapes of Manchester and Birmingham. It is regarded as the only polycentric city in the United Kingdom and is unique in that it is not one vast metropolis but rather a collection of six smaller towns and neighbouring boroughs that united as a federation in the early twentieth century. ${ }^{8}$ Stoke itself stands as the primary central location and is joined by the towns of Burslem, Hanley and Tunstall in the North, and Fenton and Longton to the South. This collection of towns, along with the borough of Newcastleunder-Lyme which borders Stoke, is more commonly referred to as The Potteries, a direct reference to the pottery and ceramic industry for which the region became renowned in the eighteenth century. ${ }^{9}$ For over a century The Potteries was perceived as being the centre of a ceramic and pottery manufacturing and production in the country, establishing a global reputation which resulted in renowned brands such as Wedgewood, Spode and Royal Doulton being distributed across the world. However, the twentieth century witnessed a decline in the demand for ceramics due to the emergence of a wider global market, whilst traditional steel, coal, and engineering industries on which the area also relied slowly faded in significance and activity. The Potteries has maintained a definitive reliance on the diminishing pottery industry and its associated social structures during the last half-century but has failed to modernise and redevelop in the same manner as other prominent nineteenth century industrial cities. This has resulted in some academics and historians suggesting that the area now remains of only local importance with minimal national influence or interest. ${ }^{10}$

The unique composition of The Potteries, with its six prominent towns, ensured the region adopted a unique identity during the nineteenth century, leading to several writers, journalists and publications from the period commenting on the arrangement of the communities, which were separated by open expanses of land, defining the area as being unlike any other industrial city. ${ }^{11}$ In 1871 an article in the publication The Leisure Hour described the region in detail:

The Potteries have the advantage of being carried on, not in one vast town, but in a number of towns, with considerable spaces of open country intervening. The stranger does not enter a dreary and interminable town, where he feels shut out from the face of nature, and doomed to converse with only bricks and mortar in their dullest and meanest shapes, as in the case of Birmingham, Manchester or Leeds. But in the Pottery towns we find ourselves surrounded by the hum of a swarming population, and by the presence of an energetic industry; and yet, at the end of nearly every street, in the cheering presence of nature's living green - of meadows, hills and woods. ${ }^{12}$

The uniqueness of the region is demonstrated by the location of the prominent buildings, features and landmarks, for example, the railway station is located in the town of Stoke and yet the largest retail area is located in Hanley, 1.5 miles away. It is also important to consider that whilst The Potteries retains a generic identity as a region, generally perceived to be that of a 'City of Pots', each of the six towns has developed its own individual distinctiveness and identity. Throughout the nineteenth century each town 'went its own way' with little or no interaction, developing their own institutions, enlarging boundaries, and attempting to improve their standing in the region. Each conurbation was self-governed by elected representatives who resided in separate town halls, whilst companies, organisations and businesses were established that were often competing against perceived rivals based in neighbouring towns. ${ }^{13}$ The suggestion of amalgamating the six towns was first proposed in the 1830 s, however, with each of them keen to protect their own individual identity, the idea 
was quickly quashed. The notion was discussed and promoted at various times throughout the remainder of the century, with no success, and it took almost 80 years of negotiation, debate and political manoeuvring before the region was unified as a federation in 1910 'on grounds of sanitation, education, and other matters of common interest'. ${ }^{14}$

Whilst the bottle shaped kilns of pottery and ceramic factories came to be synonymous with the region following the rapid industrial progress made during the seventeenth and eighteenth centuries, equally as important were the coal and clay mines of North Staffordshire. Such mines provided the fuel (coal) and raw materials (clay) which were required to ensure the continual growth of manufacturing during the period. The construction of the Trent and Mersey Canal and its sinuous branchline into Staffordshire, the Caldon, in 1779 allowed the easy and cheap transportation of material, goods and wares in and out of The Potteries, providing local industry with the perfect foundation on which to thrive. ${ }^{15}$ These transport links were further developed in 1845 when the North Staffordshire Railway company was established and proceeded to construct lines that connected the region with South Staffordshire, Cheshire, Derbyshire and Shropshire. ${ }^{16}$ However, the rapid industrial progress that The Potteries experienced during the seventeenth and eighteenth centuries saw an emphasis placed by companies and organisations on maximising production, with an increasingly lax attitude towards the health and safety of workers. Reports from the 1870s tend to suggest that the pottery industry was 'a healthy one' although there was an admission that 'there is a certain irritation to the lungs from the dust and dryness, and the fine particles of the flint and clay'. ${ }^{17}$ In reality the region was engrossed in a severe health epidemic, although the complications associated with the pottery industry would not be fully understood until the turn of the century. The death rate in the region was much higher than the national average with chest diseases, primarily bronchitis, caused through exposed work with coal and clay, among the leading causes of death. At one point, the average life span of pottery workers was ten years less than that of individuals that did not work in the industry. ${ }^{18}$ In addition to the risk of contracting chest diseases, those employed by mining companies faced other, more obvious dangers. Between 1855 and 190025 collieries were involved in fatal accidents, the gravest of which occurred during Christmas 1866 which saw 91 colliers die in Talke following the collapse of a mineshaft. ${ }^{19}$

In summary, by the early eighteenth century The Potteries consisted of six prominent towns, each with their own individual identity and defined by unique features, institutions and organisations, which were separated by great expanses of open land. The region was defined by the success of the pottery industry, which was fuelled by the coal and clay mines with wares being distributed across the country using the canal, and later railway, systems that were established. However, the work was dangerous and chest diseases caused by exposed work with coal and clay resulted in a significantly lower life expectancy in the region when compared to other areas of the country. The growth and development of the region during the nineteenth century can be measured generally by the substantial increase in population with the total number of people living in The Potteries doubling from a little over 100,000 in the late 1850 s to 250,000 in $1891 .^{20}$

\section{Early association football activities}

Whilst it was not until the 1860s that the first formal association football club was established in the region, it is clear from reports in the provincial press that some form of the game was being played throughout The Potteries prior to this period. The frequency of mentions in early regional publications, such as the Staffordshire Sentinel newspaper, during the mid-tolate 1850 s makes it clear that football was already a notable leisure pursuit in the area with games taking place during the early nineteenth century. ${ }^{21}$ Reports often related to matches taking place as part of festivals, religious occasions, for example Shrove Tuesday, fetes, and 
school outings, suggesting that football was organised on a casual, ad-hoc basis with matches occurring when the people of The Potteries had the free time to participate. ${ }^{22}$ This is particularly evident following the introduction of 'the wakes' in the region, where factories would close for one week and a short community holiday would be held. ${ }^{23}$ It presented local employees with a short break from the labours of work and it undoubtedly helped to facilitate the popularity of sporting pursuits such as football. During 'the wakes', individual towns would organise various activities in which the local community could participate and this included leisure activities such as galas, musical performances, exhibitions, and sports. Football games were commonplace during 'the wakes' and teams would be comprised of local men competing against their neighbours from within the same town. ${ }^{24}$

Football also appears to have been particularly popular amongst students attending prominent schools within the district, with scholars from St Peter's School, based in Stoke and comprising of up to 200 pupils, regularly participating in casual games when breaks occurred between lessons. The school logbook details how the local rector, Reverend Lovelace Tomlinson Stamer, presented students with a football and allowed them the use of the church grounds on which to play in $1863 .{ }^{25}$ School outings would also often result in adhoc matches taking place if space was available and when the Burslem Parish schools attended their annual trip in 1860 'several games [of football] were formed and entered into with such zeal as procured ... a good appetite for dinner'. ${ }^{26}$ The enthusiasm of students for the game continued beyond the school boundaries and by the late 1860s there are reports of 'youths' being cautioned by police officers for playing football in the street. ${ }^{27}$

It is clear that, despite no formal organisation, football activities in The Potteries were taking place in the early mid-nineteenth century. Whilst these matches were arranged on an ad-hoc basis, with no recognised clubs or known published rules, enough people were participating in football for some form of the game to be passed between generations to ensure its continuation. The context in which games took place, in the form of fetes, fairs etc., suggests that it is likely that football during this period was viewed as a form of entertainment rather than a formal contest. ${ }^{28}$ In addition to this, references to football taking place can be found relating to each of the six primary towns, indicating that local communities across the entirety of the region were aware of the game. ${ }^{29}$

It is also worth noting that the majority of the references made to football in the provincial press during this period referred to activities taking place not because of the actual games or matches themselves, but because of the factors, events or circumstance surrounding them, in a manner suggested by Swain. ${ }^{30}$ For example, in 1855 The Staffordshire Sentinel and Commercial \& General Advertiser reported an example of football activity occurring after four youths fell through the ice into a lake trying to retrieve the ball; if the youths had not required assistance then it is entirely likely that the game would have not been mentioned within the publication. ${ }^{31} \mathrm{~A}$ number of recent articles have outlined how many games of football may have gone unreported during the early nineteenth century, as newspapers would often only refer to matches taking place if a criminal offence, related or unrelated to the game, had been committed. ${ }^{32}$ Whilst academics cannot assume to use 'phantom' football reports as the basis of a sound critique that games did take place, it is a genuine consideration and raises the question of how many football activities, whether an organised match or a simple kick-a-round in the street, existed but went unreported during this period.

\section{Myths and accepted traditional narratives}

Kitching outlined the notion that the myths of origin that are apparent in popular sporting pursuits are especially tenacious, suggesting that the human love of storytelling and celebration results in an acceptance of compelling tales rather than complex evidence-based narratives. ${ }^{33}$ It is apparent throughout history that research has often attempted to search for 
and locate a single event or moment in time in order to explain how an activity, theory or concept came to be invented. For example, the myth of William Webb Ellis 'inventing' rugby at Rugby School by picking up a ball in hand and running with it is a much more captivating and romantic narrative than the suggestion that the sport came into existence as a result of an incremental process which involved emulation, various social influences, and no singular identifiable 'hero'. ${ }^{34}$ Historical research into the origins of association football at a local and regional level has recently grown, and it is foreseeable that, especially in areas where rigorous academic studies have yet to be conducted, many myths and inaccurate traditional narratives have been allowed to build up over time and be accepted as truth. ${ }^{35}$ This is particularly apparent in The Potteries, where local and oral histories have resulted in multiple exaggerated and, often false, narratives emerging, particularly surrounding the origins of the region's two prominent professional football clubs. ${ }^{36}$ It is remarkable that two prominent football clubs lack a clear understanding of how, why and who formed each club, especially as one of these clubs, Stoke City, has gained recognition as a regular Premier League competitor and FA Cup finalist in recent years. This paper challenges and explores a selection of the questionable truths surrounding the origins of the region's association football clubs.

Stoke City Football Club was undoubtedly the first formally organised association football team to be established in The Potteries, and yet the origins and early history of the club have remained unclear with multiple, contradicting narratives being proposed regarding the exact details of how and when it was formed. Stoke present their official formation date as 1863 , theoretically making it the second oldest professional football club in England, and in 2013 the club celebrated its 150 year anniversary with a variety of commemorative events. Despite this, club historians are tentative in justifying the clubs origins, going as far as to admit that 'many details remain sketchy' and that 'uncertainty clouds the actual date of formation' despite the club's crest being emblazoned with the year $1863 .{ }^{37}$ Three prominent narratives have emerged over the last 150 years attempting to provide an explanation of the club's origins, two of which suggest 1863 as the date of founding whilst another proclaims 1868. These narratives each provide a different theory as to the formation of the club, but there are some consistencies and connections across the theories. As stated earlier, football myths are prominent across the sport with some promoted simply to ensure one club retains bragging rights over another, and so it is not only important to ascertain the truth of a story, but it is also necessary to understand how and why each of the narratives became established as fact. Recognition of the origins of a myth, or pseudo fact, is important as it can help to clarify whether there were any circumstances that may later impact in other areas of the sport's history.

At Stoke, the traditionally accepted account suggests that the club was established in 1863 by four 'Old Carthusians [Former pupils of Charterhouse School]... Armand, Bell, Matthews, and Phillpott, young men who were at the time pupils at the North Staffordshire Railway' ${ }^{38}$ This narrative fits into the orthodox interpretation of the origins debate, which suggests that scholars from a prominent public school where a form of football was commonplace acted as missionaries, diffusing the game to other elements of society across the country. However, upon review it is clear that this account lacks any definitive supporting evidence as, firstly, whilst football was certainly played at Charterhouse School, the institution's records fail to identify any individuals that fit the time-period in which the club was supposedly founded. ${ }^{39}$ For example, the school registers do refer to a William MacDonald Matthews, Henry John Almond (a possible corruption of the name Armand) and a number of students with the surname Bell, but none of those listed appear to have been an appropriate age in 1863 to establish a football club in The Potteries. ${ }^{40}$ Matthews and Almond would have been aged 12 and 13, and it is improbable that either of these scholars would 
have travelled the 180 miles from their school, based in London, to North Staffordshire and then have the connections and experience to create an entirely new football team. ${ }^{41} \mathrm{In}$ addition, there are no reports relating to an association football club existing in The Potteries until late 1868 and it is unlikely that the region's only formal team would exist for five years without receiving some reference, even a minor comment, from local publications. In 1963 club historians admitted that all avenues of investigation had 'failed to provide conclusive evidence of their [Armand, Bell, Matthews, and Phillpott] origins and subsequent careers' ${ }^{42}$ The origins of this narrative can be traced to the early twentieth century and the publication in 1905 of The Book of Football. ${ }^{43}$ This appears to be the first significant publication to name the four Old Carthusians as founders of the club and, while the book has often been cited as a credible early history of the game, it is known that mistakes, inaccuracies and approximations do appear within its club history sections. The Book of Football wording is ambiguous and if read a certain way would suggest that football in general started around 1863 and that a club followed some time later. This story was repeated over the course of the next 50 years by various newspapers, publications and by club officials, helping to cement this account as the absolute truth. ${ }^{44}$ These first authors and chroniclers of football shaped how the game was perceived in the late nineteenth and early twentieth century, and it is possible that they, inadvertently or deliberately, actively promoted or relegated certain historical narratives in order to suit their own personal agenda. ${ }^{45}$ For example, a writer connected with Stoke in the early 1900s would undoubtedly have encouraged the theory that the club was formed in 1863, seeing the value of maintaining its position as the second oldest professional club in the country. It was not until the club's centenary in the 1960s that attempts were made, unsuccessfully, to clarify the validity of the Carthusian influence. It is also worth noting that no publications, newspapers or articles identified so far from the period before the publication of The Book of Football support this narrative, and that there are a number of inaccuracies and contradictions within that book's account. Most noticeably, it states that 'Stoke favoured a modified form of Rugby' failing to recognise that it would be incompatible with Carthusian ideology whilst ignoring additional evidence clearly defining that the club played an association form of the game. ${ }^{46}$ However, it should be recognised that both Matthews and Almond are central figures in other narratives which indicate the club's formation date was 1868, adding to the suggestion that the author of the Stoke feature in The Book of Football was aware of some involvement even if his detail was lacking.

Once a date becomes embedded within our collective knowledge it is often difficult to convince others that this was an error or incorrect assumption, and subsequent researchers can focus their efforts on locating material that corroborates the established truth. In Stoke's case, alternative histories began to emerge during the mid-nineteenth century attempting to prove definitively the 1863 formation date, and in 1963, as part of a Stoke City centenary supplement, the Staffordshire Sentinel referenced an account by a local man, Mr. S. Sargeant, who claimed that headmaster John Whitta Thomas instigated football in The Potteries at St. Peter's School (Stoke). Mr. Sargeant stated 'football was unknown in The Potteries before that day in 1863 when the first ball was thrown down ... I was one of those who kicked it ... the appearance of such a strange object as a football led to teachers, under Thomas, learning the game and to the forming of the Stoke club'. ${ }^{47}$ These comments had been republished from an earlier, unidentified interview and the identity of Mr. Sargeant has never been fully recorded. It is known, however, that evidence exists that disproves his version of events. Firstly, it has been identified that football activity was taking place across the region prior to 1863, disproving the theory that the origins of the game in The Potteries began at St. Peter's. The school logbook, whilst confirming that football did take place within the institution and indeed that a ball was given to the students in 1863, does not provide any suggestion that a club was established or that the game was formally organised in any manner. ${ }^{48}$ It may well be 
that Mr. Sargeant and his fellow pupils had never seen a football before one was presented at school in 1863, and it may also be true that some of those boys went on to play football for teams in subsequent years, including an incarnation of the Stoke club, but it has to be stressed that football was known and played informally by others within the region. St. Peter's does appear to have been an influence on the game in the region, and the headmaster Thomas did in later years become involved in the formative period for Stoke City, but it is clear that the activities at the institution in 1863 did not include the defining moment when the football club became established.

\section{Stoke football club}

In 1868 the Field magazine reported that 'a new club has been formed [in Stoke-upon-Trent] for the practice of the Association rules under the charge of H.J. Almond, one of the most prominent performers of the Charterhouse School XI last year'. ${ }^{49}$ This short article is the first contemporary reference that an association football club had been established and existed in The Potteries and it was followed by further reports in local publications describing Stoke Ramblers, the formal title adopted by the team, as being 'a new club, having only started this year [1868]' with the first match being played on October $171868 .{ }^{50}$ Harry John Almond, listed as Henry in the Charterhouse record, and William MacDonald Matthews were identified as the two key figures in establishing the club and they appear to be two of the Old Carthusians named in other narratives relating to an 1863 formation date - Armond (sic) and Matthews. Almond undoubtedly possessed significant experience and knowledge of football having played extensively for his school house, Gownboys, and the Charterhouse XI. ${ }^{51}$ Matthews' link with football is less clear as there are no mentions of him in the school records of having participated in any formal matches, although it is almost certain that he would have had an understanding or awareness of the rules simply by being a pupil at the school. Both of the former Charterhouse students were employed as civil engineers by the North Staffordshire Railway company, although it is likely that they were initially apprentices, and it was partly from their colleagues that they found potential players to construct a viable club. Match reports in the local and regional newspapers during the period supported by extensive census research has revealed that during its formative years the Stoke Ramblers team consisted of employees from the North Staffordshire Railway, typically civil engineers and apprentices, and a variety of assorted 'gentlemen', such as solicitors, accountants and education officials. ${ }^{52}$ Many of these individuals were already actively involved in local sport, with some recognisable members of the Stoke Cricket Club and the Stoke Victoria Athletics Club, leading to the conclusion that the formation of Stoke Ramblers may well have been the suggestion of one or both of the former public schoolboys but, as the team consisted of a mixture of individuals from the lower-middle classes with connections to other sports organisations, it appears that Stoke's formation was the result of a sporting elite that had a range of influences. It could be argued that this more closely supports the latest theories proposed by Curry and by James, where connections within sporting elites that are unique to each community, help propagate the sport. ${ }^{53}$ Demonstrating his influence and importance, Almond captained the team and scored Stoke's first goal in a 1-1 draw in the club's inaugural match against E.W. May's team, with William Eustace May later becoming a regular fixture in the early Stoke Ramblers teams. ${ }^{54}$ However, Almond departed the region soon after to follow a career in civil engineering which would see him operate in the North East of England, Spain and South America, leaving the future of the club in the hands of other members of the local sporting elite, and it may be that his absence led to the misspelling of his name in early histories with both versions of the spelling sounding similar depending on pronunciation. Almonds' departure appeared to have little impact on the development of the club with Stoke Ramblers continuing to arrange matches, operating under association 
rules as this early match report revealed 'the Congleton Club is old-established, conforming to Rugby rules, which, however they gave up on this occasion to play those of the Association, which was of advantage to the Ramblers'. ${ }^{55}$ The most significant challenge facing Stoke during those formative years was the lack of local opposition and it is apparent that the senior club officials found great difficulty in arranging games against other teams locally. Between 1868 and the summer of 1872 Stoke played only one match against a team based in The Potteries, against a Newcastle-under-Lyme representative team in $1868 .{ }^{56}$ The lack of local opposition resulted in Stoke looking further afield in search of fixtures and so games were arranged against teams located predominantly in South Staffordshire, such as Burton, Rugeley, and Whitchurch; Derbyshire, with Derby Grammar School and Derwent; and Cheshire, where opponents came from Congleton, Sandbach, and Crewe. ${ }^{57}$ The ease of travel provided by the North Staffordshire Railway, opened in 1848, facilitated the extended travelling undertaken by the club and it is clear that matches were arranged against teams situated along the service's branch lines. ${ }^{58}$ After two years the club removed the label of 'Ramblers' from their name and adopted the formal title of Stoke Football Club, though it would not be until the twentieth century when Stoke-on-Trent was granted city status that the team was renamed Stoke City. By 1872 The Potteries had its first established and fully functioning association football club and was ready for a transformational leader who could take both the club and regional football on to the next level. ${ }^{59}$

\section{The influence of Thomas Charles Slaney}

Thomas Charles Slaney became associated with Stoke in 1872, going on to be regarded as one of the key football pioneers who facilitated the development and growth of the association game across The Potteries during the nineteenth century. His involvement and impetus in Stoke Football Club as a player, captain, secretary and umpire lay the foundations that enabled the club to become a leading national sporting institution that culminated in an invitation to become founding members of the Football League in $1888 .{ }^{60}$ In addition to this, Slaney undertook the lead role in the establishment of the Staffordshire Football Association in 1877, directing the development of football in the region through seventeen years in which he acted as secretary and, later, honorary president. Beyond football he was also involved in the governance of local cricket, was a voracious political campaigner, and was regarded as something of a local celebrity, whose death compelled hundreds of people to attend his funeral. ${ }^{61}$

Born in Market Drayton, Staffordshire, in 1852, Thomas was one of four children raised by Charles and Jane Slaney. ${ }^{62}$ The family, including his younger siblings Frederick, Arthur and Frances, lived in Penkhull, a small district attached to the town of Stoke, where his father was employed by a local hotel as an ostler (a stable hand) and coachman. ${ }^{63}$ Thomas attended St. Peter's School (Stoke) where he flourished under the tutorship of the teachers and clergymen who provided education to over 200 young boys from across the town. It would appear that Slaney prospered as a student and the school logbook made multiple references to his academic acumen and accomplishments, which include him being the most prominent reader amongst his peers and winning a regional academic competition in 1863, the year headmaster John Whitta Thomas is alleged to have introduced football to the school. ${ }^{64}$ It is apparent that Thomas held Slaney in high regard, appointing him as 'monitor of the $3^{\text {rd }}$ class to assist master Boddington' and making regular comments on his progress. ${ }^{65}$ Indeed, Slaney's name features on such a regular basis within the school log book that the number of references made to him dwarf those made for other scholars. It is clear from school records that St. Peter's students actively engaged in a variety of sports which were facilitated by the teachers, clergymen and the scholars themselves, and Slaney was undoubtedly introduced to these activities at school. These sporting and leisure pursuits 
would have a substantial influence on his later life. Cricket matches were played on a regular basis, either on the schoolyard or in the grounds of the adjoining church whilst the clergymen often 'made the boys a present of a football' following lessons, suggesting some truth in Sargeant's comments but also implying that this was not as unusual an occurrence as he had stated. ${ }^{66}$ The school records indicate that cricket was formally organised by teachers who, during the summer, would often '[take] the boys out earlier than usual for a cricket match' whilst football appears to have been an ad-hoc activity arranged by like-minded students. ${ }^{67}$ The young Thomas Slaney certainly engaged in these activities and one entry into the school $\log$ reports that during a cricket contest noted that 'Slaney managed to break, accidently of course, one of the large classroom window while playing on the school yard. Made him go and order a new one in its place as punishment'. ${ }^{68}$

On January 27 1871, Slaney relocated to Birmingham where he attended Saltley Training College for two years. ${ }^{69}$ It was during this period that his association with Stoke Football Club began and he made his playing debut in a 1-0 victory against Rugeley on January $61872 .{ }^{70}$ However, his academic commitments and geographic isolation from the region, the college was based 40 miles north of Stoke, undoubtedly limited his participation in club activities and he rarely featured in the team until the autumn of 1873. Slaney's return to The Potteries at the start of 1873 coincided with his rise to prominence within the football club and he played in all scheduled matches during the 1873-74 season whilst also being elected as secretary. He continued to feature prominently during the following season and mid-way through the campaign he was also elected as captain. ${ }^{71}$ This essentially provided Slaney with the authority to operate Stoke Football Club as he saw fit, including organising the club's activities and selecting which players would play in each fixture. His prestigious status probably ensured that he chose to play at centre forward where he excelled, scoring nine goals in one game. He was described as being 'a fine and dashing player' who was 'judicious and energetic'. ${ }^{72}$

Slaney demonstrated a clear desire to promote and stimulate interest in the football club yet, under his control, Stoke appeared reluctant to participate in games against other newly formed clubs based in the local vicinity, choosing to play only five fixtures against teams located in The Potteries between 1873 and $1877 .{ }^{73}$ It appears that Slaney considered the club to be the superior team in the region and it is noticeable that, on the few occasions that local matches were arranged, only clubs with a prominent local reputation were selected for games, such as Talke Rangers. Instead, Stoke arranged fixtures against clubs based increasingly further afield including Nottingham, Birmingham, Derbyshire, Shropshire and South Staffordshire, in addition to two games against Manchester in 1876 and $1877 .{ }^{74}$ Some of these appear to be games between equals, perhaps testing Slaney's Stoke, while others seem to be more like promotional matches or games organised via existing sporting connections, such as the Manchester fixtures, where Slaney also played for Manchester clubs on occasion. ${ }^{75}$ Whilst other teams in The Potteries were content with arranging local fixtures, Slaney's desire to drive the development of his own club and of association football through a more extensive and wide-ranging fixture list provided Stoke with greater exposure that helped to establish a national reputation. This raised the club's standing within the game and Slaney's own position, empowering him to take the lead role in the development of the Staffordshire Association in 1877, and later resulting in Stoke's invitation to become founding member of the Football League in $1888 .{ }^{76}$ As noted earlier, only two of the existing county associations - Sheffield and Birmingham - claim to have been established prior to 1877, and it seems that Slaney was ahead of his time. A regular correspondent with the Athletic News, it is believed he may well have been the instigator of a suggestion to establish a regional association to take in the footballing communities of Manchester and Stoke and all areas in between in $1876 .{ }^{77}$ Whether he realised that such an area would be too great to cover 
with one association, or failed to persuade others to support his vision is not clear, but it does seem likely the result of that suggestion was a more thorough attempt at establishing the Staffordshire association the following year.

Whether it was his focus on regional matters, or simply a deterioration in his playing abilities is open to debate, but Slaney's involvement with Stoke Football Club gradually decreased during the late $1870 \mathrm{~s}$ with his final appearance as a player coming in $1880 .^{78}$ Initially he took up the role of umpiring games, and he often acted as a match official at a number of fixtures between other unconnected clubs, however, by 1883 he had stepped away entirely from all of the roles and responsibilities that he had previously held at the club. ${ }^{79}$ This was followed in 1884 by his resignation from the Staffordshire Football Association, cited as being a result of his work commitments as a teacher, and thus Slaney's immersion in football came to its conclusion. ${ }^{80} \mathrm{He}$ did re-emerge in local sport for a short period between 1889 and the mid-1890s when it was announced that he would be taking up the role of secretary for the Staffordshire County Cricket Club. ${ }^{81}$ In later years, Slaney was often described as having been a prominent cricket player, although very few contemporary references actually exist describing his cricketing performances, however it is clear that the passion for the game which he demonstrated as a schoolboy carried into his later life

Thomas Charles Slaney died on March 51898 at the age of 45 after contracting typhoid fever and pneumonia whilst travelling in Ireland. ${ }^{82}$ His death was reported by publications across the country and he was described as being 'jovial, hearty...the life and soul of every circle he joined' with 'genial manners [which] endeared to all who had the pleasure to make his acquaintance'. ${ }^{83}$ His funeral took place in Leek and attracted a substantial gathering of sympathisers from across England, to such an extent that a special train had to be arranged in order to transport over 100 people from Stoke. ${ }^{84}$ Slaney played a key role in developing association football in The Potteries, first through establishing Stoke Football $\mathrm{Cub}$ as a respected national institution, and later through his efforts in forming and directing the Staffordshire Football Association. He played a key role in laying the foundations that would allow the game to flourish across the region prior to the start of the First World War in 1914 and he is regarded as the one of the first football pioneers in the district. He may not have been the founder of the club, but he did play the lead role in developing a footballing community in Staffordshire and contributed to the growth of the game elsewhere.

\section{Establishing a football culture}

Despite the region possessing its first fully functioning association football club by $1868 ? ? ?$, the further development of a footballing community of clubs in The Potteries took several years. Whilst references to football being played during festivals, religious occasions, fetes, and school outings continued, it was not until the mid-1870s that formal clubs began to be established. In 1874 and 1875, a handful of new football clubs began to emerge with a diminutive number of matches played between teams based in Newcastle-under-Lyme, Hanley, Burslem and Talke. ${ }^{85}$ However, the following year saw a significant increase in the number of matches taking place and the summer of 1876 saw a multitude of new clubs form across the entirety of the region. ${ }^{86}$ Some clubs consisted of a collection of players from a specific town or area, such as Talke Rangers, Hanley Rangers, Wolstanton, Normacot, and Boothen Star, others were linked to local factories, for example Tunstall Royal Albion, and Minton's Star, whilst many teams were formed from educational or religious institutions, including Goldenhill Church, Burslem St. Pauls, Cobridge Collegiate, and Mr. Hemming's Day Scholars. Such was the growing popularity of the game by the start of 1876 that a number of clubs were fielding two teams on the same date in separate fixtures whilst others were venturing beyond The Potteries to face opponents from Cheshire, Stone and Stafford. ${ }^{87}$ 
The rapid increase in popularity and the number of matches being played soon resulted in a number of disputes arising between clubs regarding the rules of the game. The lack of a definitive set of rules resulted in wide ranging variations of football occurring and reports in the regional publications reference matches that last between one and five hours, and that were played by teams consisting of $11,13,15$ or 20 players. ${ }^{88}$ Some clubs agreed amicably to play under the rules as dictated by their opponents on the condition that a return match could be arranged between the two sides where the game was played under a different set of guidelines. However, other fixtures were disrupted or even abandoned altogether over disputes. A fixture in 1876 involving Talke Rangers was halted on two separate occasions following disagreements between the umpires of both clubs regarding the off side rule, whilst a match between Stoke and Derwent was described in local reports as being 'a most unpleasant game' due to disputes. ${ }^{89}$ Stoke were again involved in controversy in a fixture against Derby Grammar School when a late goal was denied after 'Mr. Aldred [a Derby player] drove the ball at the Stoke goal: but it hit against a spectator who was standing between the posts, and then bounded out again'. ${ }^{90}$ The Staffordshire Sentinel proclaimed that there was a 'desirability of having [one set of rules and] one umpire unconnected with either team' in order for greater autonomy and direction to exist within the game. ${ }^{91}$

By 1877, association football in The Potteries was flourishing with the region boasting one club of national repute, over a dozen other established local clubs, and a vast array of teams formed from industrial companies and educational institutions that played games on an ad-hoc basis. However, the lack of one definitive set of rules and the significant increase in the number of fixtures taking place on a weekly basis lead to regular disputes occurring between clubs with local publications foremost in demanding improved regulation and governance. It was Stoke Football Club that took the leading role and on April 141877 Slaney and Harry Allen facilitated a meeting between 16 local clubs at the Copeland Arms Hotel, Hanley, for 'the desirability of forming a football association for North Staffordshire and district'. ${ }^{92}$ Slaney directed the meeting and, undoubtedly having accumulated inspiration from the teams outside of the conurbation who Stoke had played previously, stated the need for an association to exist within the region and that a challenge cup competition should formed for member clubs to contest. As a comparison with Sheffield and Birmingham, both former prior to 1877, the volume of Staffordshire clubs at formation was similar to Sheffield, while Birmingham began with ten clubs. Allen, who had played for Stoke but had taken up the role of club umpire, proposed that the association should adopt Sheffield Rules to ensure that teams participating in matches were governed by only one set of regulations. The clubs that were present unanimously accepted both the introduction of a cup competition and the adoption of Sheffield rules, suggesting that the footballing community of Sheffield was more influential than the FA in Staffordshire at this time. ${ }^{93}$ The meeting established the Staffordshire Football Association, and the conclusion of the meeting saw Slaney elected as secretary of the organisation whilst Allen was nominated as a member of the executive committee. By the end of April 1877 the rules of the newly formed Association had been accepted and, later in the year, a Staffordshire Challenge Cup, valued at $£ 50$, was purchased. $^{94}$

The influence of Stoke Football Club within the Staffordshire Football Association during its early existence is easily recognisable and, to an extent, understandable with Slaney and Allen holding prestigious positions within the organisation. However, an enduring tension existed between the leading figures within the Association and members of other local clubs who perceived Stoke to have an unfair influence within the executive committee relating to decision-making and disciplinary matters. The underlying frustrations soon came to the fore and conflict appeared at times in the local press over the initial five years, however the establishment of the organisation did facilitate the further growth and development of the 
game in the region. ${ }^{95}$ During this period the Staffordshire Football Association was located in The Potteries, with inter-association fixtures taking place in Stoke and meetings taking place at the Copeland Arms Hotel in Hanley. ${ }^{96}$ However, due to the increasing number of teams from across the county affiliating to the association, it was announced that the home of county football in the region would be moved to Stafford, a more centralised location. ${ }^{97}$ The first final of the Staffordshire Challenge Cup was played between Stoke Football Club, captained by Slaney, and Talke Rangers on March 23 1878, concluding in a 1-0 victory for Stoke. ${ }^{98}$ The competition was considered to be a significant success, capturing the imagination of spectators and causing them to 'lose themselves' in excitement during the final tie, and this should be recognised as the moment when the aims of Slaney et al in establishing a footballing community had been met. ${ }^{99}$

\section{Conclusion}

This examination of the footballing communities of The Potteries demonstrates that the birth and development of association football is not a clear cut choice between the orthodox and revisionist interpretations, instead the early development of soccer in Staffordshire appears to have followed three transformational cycles. These are, an initial period where football was played at festivals, fetes and within local communities without documented formal rules, a subsequent period when former pupils of public schools encouraged others to take up the game and establish the region's first known football club, Stoke Ramblers. The third phase saw members of the middle class raised in The Potteries advance the game by establishing prominent fixtures across the Midlands, a vibrant community and a regional governing body. From this point on association football in The Potteries was established as the leading team sport after being influenced by a range of individuals, ideas and the unique composition of the region's six towns. This suggests that an understanding of the unique nature of each region will ultimately provide the answer to how football started in each community and widen our understanding of how the game developed nationally.

This paper has also demonstrated that within sport and leisure history some of the work produced by early chroniclers has been accepted as fact with little consideration of whether their original writing contains errors, approximations or has been written from a particular bias. For example, research disseminated within this article has identified that within the traditional accounts of Stoke City's origins and formation, names have been misconstrued and a false five-year period has been added to the club's history, leading to a misunderstanding of the early history of one of football's earliest prominent clubs. This demonstrates that more regional studies are required to further our understanding of the national picture, and that these should be directed towards exploring the individuals that developed and promoted the sport within local communities.

\footnotetext{
Notes

1 "Euro 2016", BBC Sport, accessed October 1, 2016, http://www.bbc.co.uk/sport/football/36755192.

2 Dunning and Sheard, Barbarians, Gentleman and Players.

3 Taylor, The Association Game.

${ }^{4}$ Orthodox examples include Dunning and Sheard, Barbarians, Gentleman and Players; Curry and Dunning, 'The Power Game'; Curry and Dunning, 'The "Origins of Football Debate" and the Early Development of the Game in Nottinghamshire'. Soccer and Society (2015): accessed Septemer 10, 2016. doi:10.1080/14660970.2015.1067801; Curry and Dunning, 'The Problem with Revisionism'.

${ }^{5}$ Revisionist examples include Swain and Harvey, 'On Bosworth Field or'; Goulstone, 'The Working Class Origins'; Swain, 'The Origins of Football'; Harvey, 'The Public Schools and'. Consensus examples include Collins, 'Early Football and the'; James. 'Historical Frameworks and Sporting Research'. The International Journal of the History of Sport. (2016): accessed Septemer 12, 2016. DOI: 10.1080/09523367.2016.1221816; Kitching, 'The Origins of Football'.
} 
${ }^{6}$ James and Day, 'The Emergence of an Association Football Culture in Manchester'; Kennedy. Football in Victorian Liverpool'; Swain, 'Football in Nineteenth Century Lancashire'; Curry, 'Football Spectatorship'.

${ }^{7}$ Martin, A Potter's Tale; Kent, The Valiants' Years.

${ }^{8}$ Jenkins, 'A History of the County of Stafford', 252-258.

9 Jenkins, 'A History of the County of Stafford', 252-258; Macauley, 'A Glimpse at The Potteries'.

${ }^{10}$ Edensor, Reclaiming Stoke-on-Trent; Jayne, 'Culture that works?', 200.

${ }^{11}$ Macauley, 'A Glimpse at The Potteries'.

${ }^{12}$ Ibid.

${ }^{13}$ Jenkins, $A$ History of the County of Stafford, 252-258; Taylor, Stoke-on-Trent.

${ }^{14}$ Jenkins, A History of the County of Stafford, 252-258.

${ }^{15}$ Rice, The Lost City.

${ }^{16}$ Christiansen and Miller, The North Staffordshire Railway.

${ }^{17}$ Macauley, 'A Glimpse at The Potteries'.

${ }^{18}$ Tupholme and Leake, The Sentinel Story.

${ }^{19}$ Ibid.

${ }^{20}$ Staffordshire Sentinel, July 25, 1891, 2; Staffordshire Sentinel and Commercial \& General Advertiser, January 6, 1855, 7; March 24, 1855, 6; August 29, 1863, 5.

${ }^{21}$ Example include Staffordshire Sentinel and Commercial \& General Advertiser, February 3, 1855, 5; June 16, 1860, 4; August 25, 1860, 4; September 8, 1860, 4.

${ }^{22}$ Staffordshire Advertiser, September 21, 1844, 3; Staffordshire Sentinel and Commercial \& General Advertiser, June 16, 1860; Thomas, St. Peter's High School Logbook and Records.

${ }^{23}$ Walton, 'The Demand for Working-Class Seaside Holidays'.

${ }^{24}$ Staffordshire Sentinel and Commercial \& General Advertiser, August 9. 1856.

${ }^{25}$ Thomas, St. Peter's High School Logbook and Records.

${ }^{26}$ Staffordshire Sentinel and Commercial \& General Advertiser, August 25, 1860, 4.

${ }^{27}$ Staffordshire Sentinel and Commercial \& General Advertiser, April 3, 1869, 8.

${ }^{28}$ James and Day, 'The Emergence of an Association Football Culture in Manchester'.

${ }^{29}$ Examples include Staffordshire Advertiser, September 21, 1844, 3; Staffordshire Sentinel and Commercial \& General Advertiser, August 9, 1856; June 16, 1860, 4; August 1860, 4; September 8, 1860, 4; August 29, 1863, 5; Surrey Advertiser, July 20, 1864, 3; Thomas, St. Peter's High School Logbook and Records.

${ }^{30}$ Swain, 'The Origins of Football', 301.

${ }^{31}$ Staffordshire Sentinel and Commercial \& General Advertiser, February 3, 1855, 5.

${ }^{32}$ Swain, 'The Origins of Football', 301.

${ }^{33}$ Kitching, 'The Origins of Football', 128.

${ }^{34}$ Ibid.

${ }^{35}$ Martin, A Potter's Tale; Kent, The Valiants' Years.

${ }^{36}$ Martin, A Potter's Tale; Matthews, The Encyclopaedia of Stoke; Kent, The Valiants' Years; Kent, The Port Vale Record.

37 "In The Beginning", Stoke City Football Club, accessed August 20, 2016, http://www.stokecityfc.com/club/history/1863.aspx.

${ }^{38}$ The Book of Football (London: Amalgamated Press, 1906).

${ }^{39}$ Arrowsmith, Charterhouse Register: 1769 -1872; Census Returns, Paddington, 1861 (RG 9/12); Census Returns, Kensington, 1861 (HO 107/1468).

${ }^{40}$ Arrowsmith, Charterhouse Register: 1769 -1872.

${ }^{41}$ Ibid.

${ }^{42}$ Buxton, Stoke City Centenary Handbook.

${ }^{43}$ The Book of Football.

${ }^{44}$ Staffordshire Advertiser, May 13, 1933, 3; Sheffield Independent, June 18, 1908, 11.

${ }^{45}$ Hay, 'History of Football Scotland'; James and Day, 'The Emergence of an Association Football Culture in Manchester'.

${ }^{46}$ The Book of Football; Birmingham Daily Post, December 11, 1868; The Sportsman, December 9, 1868.

${ }^{47}$ Staffordshire Sentinel; Stoke City Football Club Centenary Supplement, April 1963.

${ }^{48}$ Thomas, St. Peter's High School Logbook and Records.

${ }^{49}$ The Field, September 26, 1868; Birmingham Daily Post, December 11, 1868, 3.

${ }^{50} \mathrm{Ibid}$.

${ }^{51}$ Arrowsmith, Charterhouse Register: 1769 -1872; The Sportsman, October 17, 1867, 4; Pall Mall Gazette, March 2, 1868, 9. 
${ }^{52}$ Martin, A Potter's Tale. Examples include Census Returns, Longford, 1881 (RG 11/2530); Census Returns, Shelton, 1871 (RG 10/2862); Census Returns, Newcastle-under-Lyme, 1871 (RG 10/2834); Census Returns, Shelton, 1871 (RG 10/2862); Census returns, Stoke-on-Trent (RG 10/2853).

${ }^{53}$ Curry and Dunning, 'The Problem with Revisionism'; James and Day, 'The Emergence of an Association Football Culture in Manchester'.

${ }^{54}$ Martin, A Potter's Tale; Kent, The Valiants' Years; The Sportsman, December 31, 4.

${ }^{55}$ The Sportsman, December 9, 1868.

${ }^{56}$ The Sportsman, January 7, 1869.

${ }^{57}$ Example include The Sportsman, December 9, 1868, 4; Shrewsbury Chronicle, December 23, 1870, 7; Derbyshire Advertiser and Journal, November 2, 1871, 7; Staffordshire Advertiser, January 13, 1872.

${ }^{58}$ Christiansen and Miller, The North Staffordshire Railway.

59 Staffordshire Sentinel and Commercial \& General Advertiser, October 15, 1870; Bass and Riggio, Transformational Leadership.

${ }^{60}$ Taylor, The Leaguers: The Making of Professional Football in England 1900-1939; Manchester Courier and Lancashire General Advertiser, April 18, 1888, 3; Sheffield Independent, 19 April, 1888, 7; Nottingham Evening Post, April 18, 1888, 2.

${ }^{61}$ Leek Post \& Times, March 12, 1898.

${ }^{62}$ Census Return, Penkhull, 1861 (RG 9/1938); Census Returns, Penkhull 1871 (RG 10/2869).

${ }^{63}$ Ibid.

${ }^{64}$ Thomas, St. Peter's High School Logbook and Records.

${ }^{65}$ Ibid.

${ }^{66}$ Ibid.

${ }^{67}$ Ibid.

${ }^{68}$ Ibid.

${ }^{69}$ Leek Post \& Times, March 12, 1898;Thomas, St. Peter's High School Logbook and Records.

${ }^{70}$ Leek Post \& Times, March 12, 1898.

${ }^{71}$ The Athletic News, March 3, 1877.

72 Leek Post \& Times, March 12, 1898; Matthews, Encyclopaedia of Stoke City, 6; Martin, A Potter's Tale.

${ }^{73}$ Examples include Staffordshire Sentinel, October 21, 1874; March 29, 1875, 3; November 26, 1875, 4; February 7, 1876, 2; Staffordshire Sentinel and Commercial \& General Advertiser, February 12, 1876, 7.

${ }^{74}$ Examples include Nottinghamshire Guardian, December 5, 1873, 7; Eddowes's Journal and General Advertiser for Shropshire, January 28, 1874, 7; Staffordshire Sentinel, October 28, 1874, 3; November 5, 1874, 2; March 20, 1877.

${ }^{75}$ Manchester Courier, April 8, 1878.

${ }^{76}$ Staffordshire Sentinel and Commercial \& General Advertiser, April 21, 1877, 5.

77 The Athletic News, October 14, 1876, 5.

${ }^{78}$ Staffordshire Sentinel, February 16,1880.

${ }^{79}$ The Athletic News, October 19. 1881; Staffordshire Advertiser, October 21, 1882.

${ }^{80}$ Birmingham Daily Post, August 31, 1891; Leek Post \& Times, March 12, 1898.

${ }^{81}$ Staffordshire Sentinel, May 4, 1889.

${ }^{82}$ Leek Post \& Times, March 12, 1898.

${ }^{83}$ Ibid.

${ }^{84}$ Ibid.

${ }^{85}$ Example include Staffordshire Sentinel, February 4, 1875, 3; February 11, 1875, 3; February 16, $1875,2$.

${ }^{86}$ Staffordshire Sentinel and Commercial \& General Advertiser, November 4, 1876, 8; Staffordshire Sentinel, November 10, 1876, 2.

87 Staffordshire Sentinel, November 13, 1876, 3.

${ }^{88}$ Examples included within Speake, One Hundred Years of County Football.

${ }^{89}$ Staffordshire Sentinel, March 25, 1875, 3; Staffordshire Sentinel, March 29, 1875, 3.

${ }^{90}$ Derbyshire Advertiser and Journal, November 2, 1871, 7.

${ }^{91}$ Staffordshire Sentinel, March 29, 1875, 3.

${ }^{92}$ Staffordshire Sentinel and Commercial \& General Advertiser, April 21, 1877, 5.

${ }^{93}$ Staffordshire Sentinel and Commercial \& General Advertiser, April 21, 1877, 5; Staffordshire Advertiser, September 1, 1877, 4; Staffordshire Sentinel, March 25, 1878, 4.

94 Staffordshire Advertiser, September 1, 1877, 4; Staffordshire Sentinel, March 25, 1878, 4.

${ }^{5}$ Staffordshire Sentinel, March 11, 1878; Speake, One Hundred Years of County Football; Alcock, The Football Annual.

${ }^{96}$ Staffordshire Sentinel and Commercial \& General Advertiser, April 21, 1877, 5. 
${ }^{97}$ Speake, One Hundred Years of County Football; Staffordshire Sentinel and Commercial \& General Advertiser, September 29, 1877, 6.

${ }_{98}$ Staffordshire Sentinel, March 25, 1878, 4.

${ }^{99}$ Ibid.

\section{References}

Alcock, Charles. The Football Annual. London, Lillywhite, 1872.

The Athletic News.

Bass, Bernard, and Ronald Riggio. Transformational Leadership. New Jersey: Lawrence Erlbaum Associates, 2006.

Birmingham Daily Post.

The Book of Football: A Complete History and Recored of the Association and Rugby Games 1905-06. (London: Amalgamated Press, 1906).

Buxton, Peter. Stoke City Football Club Centenary Handbook, 1863-1963: A History of the Clove Over the Past One Hundred Years. Nottingham: Pyramid Press, 1963.

Collins, Tony. 'Early Football and the Emergence of Modern Soccer, 1840-1880'. International Journal of the History of Sport, 32, no 9 (2015): 1127 - 1142.

Christiansen, Rex, and Robert Miller. The North Staffordshire Railway. Exeter: David and Charles, 1971.

Curry, Graham. 'Football Spectatorship in mid-to-late Victorian Sheffield'. Soccer and Society, 8, no 2-3 (2007): 185-204.

Curry, Graham and Eric Dunning. 'The Power Game: Continued Reflections on the Early Development of Modern Football'. The International Journal of the History of Sport,33, no 3 (2016): 239 - 250.

Curry, Graham, and Eric Dunning. 'The Problem with Revisionism: How New Data on the Origins of Modern Football have led to Hasty Conclusions'. Soccer and Society, 14, no 4 (2013): 429 - 445.

Derbyshire Advertiser and Journal.

Dunning, Eric, and Kenneth Sheard. Barbarians, Gentleman and Players. London: Routledge, 2005.

Eddowes's Journal and General Advertiser for Shropshire.

Edensor, Tim. Reclaiming Stoke-on-Trent: Leisure, Spaces and Identity in The Potteries. Stoke-on-Trent: Staffordshire University Press.

The Field.

Goulstone, John. 'The Working Class Origins of Modern Football'. The International Journal of the History of Sport, 17, no 1 (2000): $134-143$.

Harvey, Adrian. 'The Public Schools and Organised Football in Britian: Fresh Perspectives on Old Paradigms'. The International Journal of the History of Sport, 33, no 3 (2016): 272 - 288.

Jayne, Mark. 'Culture that Works? Creative Industries in a Working Class City'. Capital and Class, 28, no 3 (2004): 199-210.

James, Gary, and Dave Day. 'The Emergence of an Association Football Culture in Manchester, 1840-1884'. Sport in History, 36, no1 (2014): 49-74.

Jenkins, J.G. A History of the County of Stafford: Volume 8. London: Victoria County History, 1963. 
Kent, Jeff. The Port Vale Record: 1879-1993. Alsager: Witan Books, 1993.

Kent, Jeff. The Valiants' Years: The Story of Port Vale. Stafford: Witan, 1990.

Kennedy, David. 'Locality and Professional Football Club Development: The Demographics of Football Club Support in Late Victorian Liverpool'. Soccer and Society, 5, no 3 (2004): 371-91.

Kitching, Gavin. 'The Origins of Football: History, Ideology and the Making of 'The People's Game'. History Workshop Journal, 79, no 79 (2015): 127-153.

Leek Post \& Times.

Macauley, James. 'A Glimpse at The Potteries'. The Leisure Hour, 998 (1871): 94-96.

Manchester Courier and Lancashire General Advertiser.

Martin, Wade. A Potter's Tale: The Story of Stoke City Football Club. Buckingham: Sporting \& Leisure Press, 1988 .

Matthews, Tony. The Encyclopaedia of Stoke City, 1868-1994. West Bromwich: The Lion Press, 1994.

Nottingham Evening Post.

Nottinghamshire Guardian.

Pall Mall Gazette.

Rice, Matthew. The Lost City of Stoke-on-Trent. London, Frances Lincoln, 2010.

Sheffield Independent.

Shrewsbury Chronicle.

Speake, Robert. One Hundred Years of County Football - The Staffordshire Football Association Centenary, 1877-1977. Stafford: Staffordshire Football Association, 1977.

The Sportsman.

Staffordshire Advertiser.

Staffordshire Sentinel.

Staffordshire Sentinel and Commercial \& General Advertiser.

Surrey Advertiser.

Swain, Peter. 'Cultural Creativity and Football in Nineteenth Century Lancashire'. Sport in History, 28, no 4 (2008): 566-582.

Swain, Peter. 'The Origins of Football Debate: The Evidence Mounts'. The International Journal of the History of Sport, 32, no 2 (2015): 1841-1851.

Taylor, Alan. Stoke-on-Trent: A History. Gloucestershire: Phillimore, 2003.

Taylor, Matthew. The Association Games: A History of British Football. New Jersery: Pearson Education, 2008.

Taylor, Matthew. The Leaguers: The Making of professional Football in England 1900-1939. Liverpool: Liverpool University Press, 2005. 
Thomas, John Whitta. St. Peter's High School Logbook and Records.

Tupholme, John, and David Leake. The Sentinel Story: 1873-1973. Hanley: James Heap Publishing, 1973.

Walton, John. 'The Demand for Working-Class Seaside Holidays in Victorian England'. The Economic History Review, 34, no 2 (1981): 249 - 265. 